\title{
Novel insights into the volatile content of arc magmas recorded in the deep roots of Kohistan arc
}

\author{
B. URANN ${ }^{1}$,V.LE ROUX ${ }^{1}$, O. JAGOUTZ ${ }^{2}$, E. J. CHIN ${ }^{3}$, M. \\ D. BEHN $^{4}$, O. MÜNTENER ${ }^{5}$ \\ ${ }^{1}$ Geology and Geophysics Department, Woods Hole \\ Oceanographic Institution, Woods Hole, MA, USA \\ ${ }^{2}$ Department of Earth, Atmospheric, and Planetary Sciences, \\ ${ }^{3}$ Massachusetts Institute of Technology, Cambridge, MA \\ 4 Scripps Institution of Oceanography, University of \\ California San Diego, La Jolla, CA, USA \\ ${ }^{5}$ Department of Earth and Environmental Sciences, Boston \\ College, Chestnut Hill, Massachusetts, USA \\ ${ }^{6}$ Institue of Earth Sciences, University of Lausanne, CH- \\ 1015, Lausanne, Switzerland
}

Crustal processes related to vapor saturation, diffusive reequilibration, assimilation and fractional crystallization modulate the water content of arc magmas, limiting the utility of melt inclusion studies. In an effort to better constrain arc magma volatile abundances, we performed in-situ secondary ion mass spectrometry measurements of $\mathrm{H}_{2} \mathrm{O}$ on pyroxenes from cumulates from the Chilas Complex $(\sim 0.6 \mathrm{GPa})$ and the Southern Plutonic Complex (SPC, 0.8-1.5 GPa) in the Kohistan paleo-arc section (NW Pakistan). Previous studies have qualitatively estimated the water content of parental melts concluding that the Chilas cumulates fractionated from damp melts whereas SPC cumulates are considered to have crystallized from wet melts. Using published compositionally-dependent partition coefficients, our SIMS data allow us to quantitatively constrain the water content of the melts from which the cumulates crystalized. Chilas gabbronorites yield equilibrium melt water concentrations of $1.6 \pm 0.1 \mathrm{wt} \% \mathrm{H}_{2} \mathrm{O}$, whereas hydrous SPC garnet pyroxenites give equilibrium melt $\mathrm{H}_{2} \mathrm{O}$ concentrations of $8.3 \pm 0.7$ wt $\%$. During fractional crystallization, melt $\mathrm{H}_{2} \mathrm{O}$ contents may increase to nearly $20 \mathrm{wt} \%$, consistent with the high solubility of water in silicate melts determined from experimental studies, yet rarely if ever recorded in melt inclusions. 